\title{
Disparate Impact Analysis of the Critical \\ Hire-Personality Assessment
}

\author{
Tony Tatman \\ Critical Hire, PLC \\ United States
}

Received: Jan. 23, 2022 Accepted: Feb. 28, 2022 Online published: Mar. 1, 2022

doi:10.5296/ijhrs.v12i1.19491 URL: https://doi.org/10.5296/ijhrs.v12i1.19491

\begin{abstract}
Pre-employment personality testing has become widely used across a variety of work settings. A relatively new area where pre-employment personality testing is being implemented is in the field of community-based corrections (CBCs). One instrument being used in CBCs for this purpose is the Critical Hire-Personality Assessment (CH-PA). Federal laws and hiring guidelines have been enacted that impact the use of pre-employment personality assessments such as the CH-PA. The Age Discrimination in Employment Act and Title VII of the Civil Rights Act of 1964, for example, prohibit employment discrimination based on gender, age, and racial/ethnic status. The present study examines if the $\mathrm{CH}-\mathrm{PA}$ complies with federal laws and guidelines regarding employee selections by examining the degree to which the CH-PA scale and subscale scores differ based on CBC officer gender, age, and racial/ethnic status. Results revealed that the CH-PA scales and subscales do not differ in a manner that would significantly contribute to a disparate or adverse impact based on CBC officer applicant gender, age, and racial/ethnic status. Implications of these findings for CBC agencies are discussed.
\end{abstract}

Keywords: pre-employment testing, personality testing, disparate impact, community-based corrections, probation officer, parole officer

\section{Introduction}

The practice of evaluating personality traits during the pre-employment hiring process has become widely used across a variety of work settings (Ones et al., 2007). A relatively new area where pre-employment personality assessments have been implemented is within the field of community-based corrections (CBCs). CBCs, or otherwise referred to as departments of probation or parole, provide supervision and rehabilitative services to individuals on pretrial release, work release, probation, and parole. Individuals providing services to these individuals include probation and parole officers, residential officers, and treatment providers. 
This group of providers will be collectively referred to throughout the rest of this paper as CBC officers. Pre-employment personality tests have been identified as helping CBCs identify traits associated with $\mathrm{CBC}$ officer job performance in this unique and demanding profession (Tatman, 2019b; Tatman, 2021).

State and federal regulations have been enacted that dictate the proper use and requirements for pre-employment personality testing. In 1978, the Equal Employment Opportunity Commission (EEOC) adopted the Uniform Guidelines on Employee Selection Procedure (UGESP, 1978) which provides guidelines for the proper use of tests and other employee selection procedures. Based on the UGESP, selection procedures, such as pre-employment personality tests, must show evidence of their validity, reliability, and applicability to the specific job and population for which it is being used. After an exhaustive search of pre-employment personality assessments used with $\mathrm{CBC}$ officers or within $\mathrm{CBC}$ settings only the Critical Hire-Personality Assessment (CH-PA; Tatman, 2019a) was identified as meeting this UGESP guideline.

In addition to the UGESP, the Age Discrimination in Employment Act (ADEA) and Title VII of the Civil Rights Act of 1964 are two additional federal guidelines that prohibit employment discrimination based on gender, age, and racial/ethnic status. Based on these guidelines and laws, hiring agencies and evaluators are responsible for ensuring their hiring processes, which include pre-employment personality assessments, do not contribute to a disparate impact on protected populations (e.g., minorities, females, and individuals over the age of 40). Disparate impact, or sometimes called adverse impact, is a form of discrimination identified by the EEOC that occurs when an agency's hiring practices discriminate against an applicant based on their gender, age, or race/ethnicity. Although the $\mathrm{CH}-\mathrm{PA}$ has been identified as being compliant with UGESP standards, no research has been conducted that measures the degree to which it complies with ADEA or Title VII standards. Specifically, research has not been conducted that evaluates whether the CH-PA's scales and/or subscales may contribute to an adverse impact for CBC officer applicants based on their gender, age, and/or racial/ethnic status. Therefore, the purpose of this study is to measure the degree to which the CH-PA scales and subscales contribute to an adverse impact based on CBC officer applicant gender, age, and/or racial/ethnic status. Results of this study could provide valuable information for $\mathrm{CBC}$ hiring agencies using the $\mathrm{CH}-\mathrm{PA}$ by providing empirical evidence about whether or not $\mathrm{CH}-\mathrm{PA}$ scale and subscale scores significantly differ based on examine gender, age, and racial/ethnic status. This information would be valuable to $\mathrm{CBC}$ hiring agencies because it speaks to the degree to which the CH-PA complies with federal hiring guidelines.

\section{Method}

\subsection{Measures}

\subsubsection{The Critical Hire-Personality Assessment}

The Critical Hire-Personality Assessment (CH-PA; Tatman, 2019a) is a pre-employment, personality assessment developed on, and validated with, new and incumbent CBC officers. The CH-PA is a 72-item assessment containing five distinct, and Five-Factor Model (Digman, 
1990; Wiggins, 1996) consistent, personality scales and 17 subscales. The five CH-PA scales are Stress Response, which is made up of three subscales (Impulsivity, Irritability, and Social Discomfort); Extraversion, made up of four subscales (Warmth, Assertiveness, Gregariousness, and Activity Level); Flexibility, made up of two subscales (Intellectual Curiosity and Openness to Change); Agreeableness, which is made up of four subscales (Empathy, Trust, Modesty, and Cooperation); and Conscientiousness, which is made up of four subscales (Drive \& Self-Discipline, Dependability \& Reliability, Organization, and Deliberation). CH-PA scores are reported as T scores $(M=50, S D=10)$, and questions are anchored with a five-point, Likert scale (e.g., Strongly Agree to Strongly Disagree). The $\mathrm{CH}-\mathrm{PA}$ was developed to be a screening tool that provides hiring agencies with information about the applicant's personality traits and tendencies early in the hiring process and is not intended to be the sole determinant for screening out applicants from consideration (Tatman, 2019a).

Researchers have identified that the CH-PA's scales and subscales are significantly correlated with, and can adequately predict, CBC officer job performance ratings (Tatman, 2019a; Tatman, 2022). Tatman (2019a; 2022) also found that the CH-PA scales and subscales have adequate internal consistency, test-retest reliability, and convergent validity with the NEO Personality Inventory-Revised (Costa \& McCrae, 1992). Tatman (2019a) further reported that three of the five $\mathrm{CH}-\mathrm{PA}$ scales, and 8 of the 16 subscales, produced adequate receiver operator curve areas in relation to $\mathrm{CBC}$ officer job performance ratings. Tatman (2022) also reported significant correlations between $\mathrm{CH}-\mathrm{PA}$ scale and subscale scores with supervisor ratings of $\mathrm{CBC}$ officer job performance. These findings help support the reliability, validity, and applicability of the $\mathrm{CH}-\mathrm{PA}$ with $\mathrm{CBC}$ officers and provide empirical evidence that many of the scales and subscales are predictive of CBC officer job performance.

\subsection{Participants}

The sample used in this study came from a convenience sample of three Midwestern CBC agencies naturally using the CH-PA as part of their hiring process, providing naturally occurring archival data for this study. Individuals in this sample were applying for CBC job openings and completed the CH-PA during the pre-conditional offer phase of the agency's hiring process. During the application process the applicants were provided a digital link to complete the CH-PA online. All participants provided consent that their pre-employment testing data could be used for research purposes. The sample for this study consisted of 53 CBC applicants. These participants consisted of 26 individuals applying for residential officer positions, 15 individuals applying for probation and parole officer positions, seven for community treatment coordinator positions, two for clerical positions, two for CBC supervisor positions, and one person applying for a certified law enforcement position. Twenty-three participants were male and 30 were female. Race/ethnicity for the sample consisted of 39 Caucasian, eight African American, and six Hispanic participants. The sample had a mean age of 34.47, with a range of 21 to 55 .

\subsection{Procedures}

Independent t-tests were conducted to measure the degree to which $\mathrm{CH}$-PA scale scores 
differed based on gender, age, or racial/ethnic status.

\section{Results}

A series of independent samples t-tests were conducted to measure whether CH-PA scale scores significantly differed based on gender, age, or racial/ethnic status.

\section{Gender Differences}

T-tests results show that, other than for the Irritability subscale, no significant differences in $\mathrm{CH}-\mathrm{PA}$ scale or subscale scores were found between males and females (Table 1). Regarding the difference in Irritability scores found in this study, female CBC officers appeared to score significantly higher on the Irritability subscale compared to male CBC officers. A post hoc Cohen's d effect size calculation was conducted to measure the magnitude of this difference. Results from this post hoc analysis provided a Cohen's d of .68, suggesting that this difference between male and female Irritability scores was moderate in magnitude (Cohen, 1988).

\section{Age Differences}

The ADEA identifies people who are 40 years of age or older as a protected population. Therefore, to be consistent with this ADEA guideline, the following t-test comparisons were based on participants who were 40 or older $(n=36)$ against participants under $40(n=17)$. Results of these analyses revealed that, other than for the Flexibility scale and its Openness to Change subscale, CH-PA scale and subscale scores did not significantly differ based on applicant age (Table 2). When looking at the differences found in this study individuals who were 40 years of age or older scored significantly higher on Flexibility and Openness to Change compared to younger CBC officers. Post hoc Cohen's d effect size calculations were then conducted to measure the magnitude of these differences. Results from these post hoc analyses provided a Cohen's $d$ of .60 regarding the age difference pertaining to the Flexibility scale and .54 for the Openness to Change subscale. These post hoc results suggest that these differences between CBC officers 40 years of age or old compared to officers under 40 were moderate in their magnitude (Cohen, 1988).

\section{Racial/Ethnic Status Differences}

Independent samples t-tests were also conducted to investigate the degree to which the $\mathrm{CH}-\mathrm{PA}$ scale scores significantly differed based on race/ethnicity. Due to the relatively small number of minority participants in the various racial/ethnic groups in this sample, minorities were combined into a single "Minority" group $(n=14)$. Caucasians $(n=39)$ will be referred to throughout the rest of this paper as the "Majority". This process of dichotomizing racial status is consistent with prior pre-employment personality and integrity research (Tatman, 2022; Tatman \& Huss, 2020). Results revealed that, other than for a significant difference on the Deliberation subscale, there were no significant differences between racial minorities and majority participants (Table 3). The difference observed consisted of Minority CBC officers scoring significantly higher on Deliberation compared to Majority officers. A post hoc Cohen's d effect size calculation was then conducted to measure the magnitude of this 
difference. Results provided a Cohen's d of .77. These results suggest that the difference found between Majority and Minority CBC officers' Deliberation subscale scores was moderate in magnitude (Cohen, 1988).

Table 1. Gender Means, Standard Deviations, t-Tests, and Effect Size

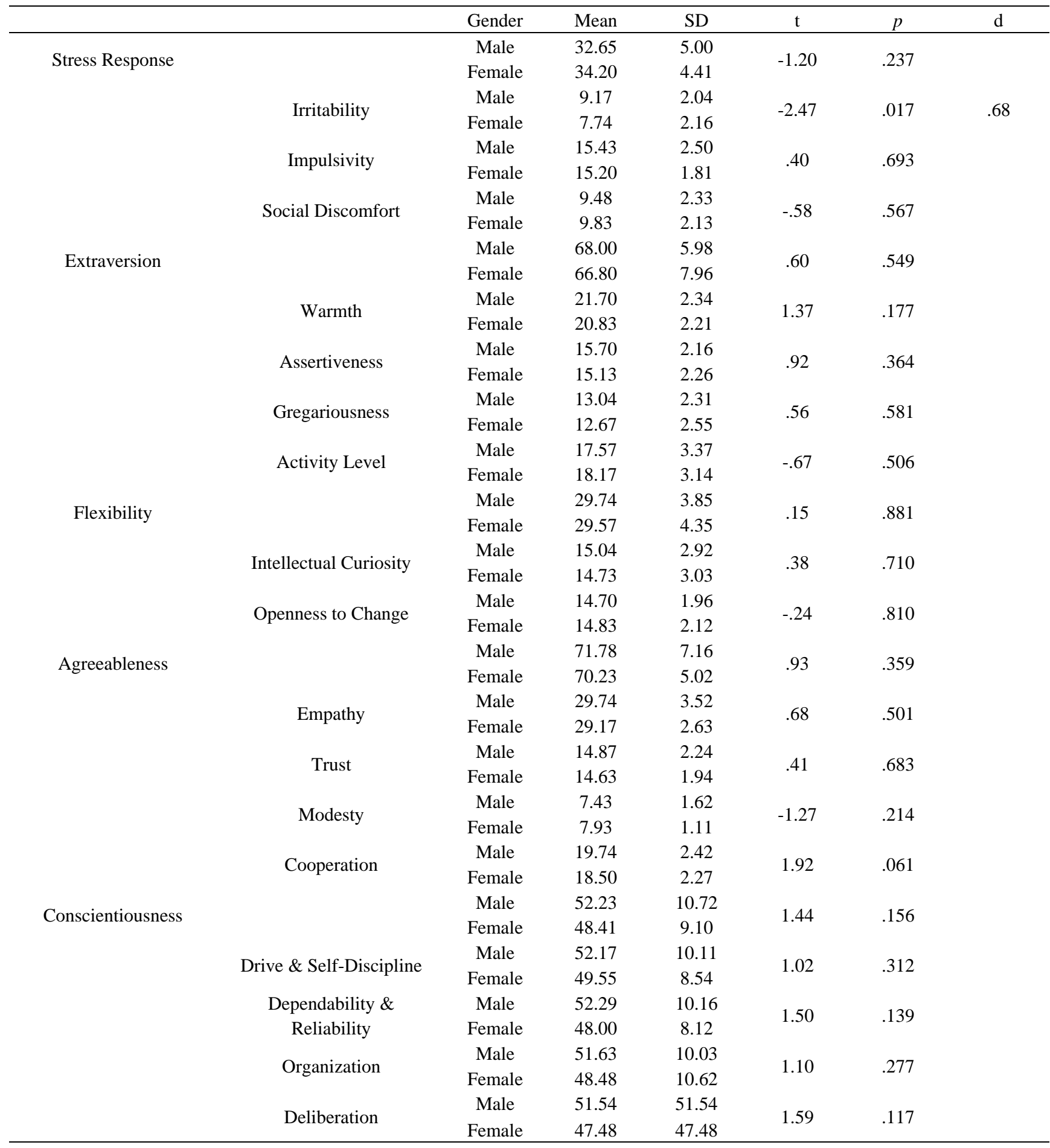


Table 2. Age Means, Standard Deviations, and t-Tests and Effect Sizes

\begin{tabular}{|c|c|c|c|c|c|c|c|}
\hline & & Age & $M$ & $S D$ & $t$ & $p$ & $d$ \\
\hline \multirow{8}{*}{ Stress Response } & & Under 40 & 33.22 & 4.96 & \multirow[b]{2}{*}{-.69} & \multirow{2}{*}{.495} & \\
\hline & & $40+$ & 34.18 & 4.11 & & & \\
\hline & \multirow{2}{*}{ Irritability } & Under 40 & 8.28 & 2.12 & \multirow{2}{*}{-1.31} & \multirow{2}{*}{.195} & \\
\hline & & $40+$ & 9.12 & 2.29 & & & \\
\hline & \multirow{2}{*}{ Impulsivity } & Under 40 & 15.25 & 2.13 & \multirow{2}{*}{-.26} & \multirow{2}{*}{.798} & \\
\hline & & $40+$ & 15.41 & 2.15 & & & \\
\hline & \multirow{4}{*}{ Social Discomfort } & Under 40 & 9.69 & 2.24 & \multirow{2}{*}{.07} & \multirow{2}{*}{.943} & \\
\hline & & $40+$ & 9.65 & 2.20 & & & \\
\hline \multirow{10}{*}{ Extraversion } & & Under 40 & 68.42 & 7.05 & \multirow{2}{*}{1.66} & \multirow{2}{*}{.104} & \\
\hline & & $40+$ & 65.00 & 6.95 & & & \\
\hline & \multirow{2}{*}{ Warmth } & Under 40 & 21.39 & 2.41 & \multirow{2}{*}{0.84} & \multirow{2}{*}{.407} & \\
\hline & & $40+$ & 20.82 & 2.04 & & & \\
\hline & \multirow{2}{*}{ Assertiveness } & Under 40 & 15.36 & 2.42 & \multirow{2}{*}{-.08} & \multirow{2}{*}{.939} & \\
\hline & & $40+$ & 15.41 & 1.77 & & & \\
\hline & \multirow{2}{*}{ Gregariousness } & Under 40 & 13.06 & 2.41 & \multirow{2}{*}{.98} & 321 & \\
\hline & & $40+$ & 12.35 & 2.47 & & .331 & \\
\hline & Activity Level & Under 40 & 18.61 & 2.91 & 242 & 019 & \\
\hline & Activity Lever & $40+$ & 16.41 & 3.43 & 2.42 & & \\
\hline Flovibility & & Under 40 & 30.44 & 3.57 & 214 & 027 & 60 \\
\hline Flexibility & & $40+$ & 27.94 & 4.72 & 2.14 & (03/ & .60 \\
\hline & Intolloctuol Curiocity & Under 40 & 15.25 & 2.61 & 130 & 173 & \\
\hline & Intellectual Curiosity & $40+$ & 14.06 & 3.53 & 1.38 & .173 & \\
\hline & Ononnecs to Chonge & Under 40 & 15.19 & 1.82 & 20 & 027 & 54 \\
\hline & Openness to C nange & $40+$ & 13.88 & 2.23 & 2.20 & . 021 & .54 \\
\hline A greeableness & & Under 40 & 71.08 & 6.24 & 31 & 758 & \\
\hline Agreedoreness & & $40+$ & 70.53 & 5.71 & .01 & .158 & \\
\hline & & Under 40 & 29.42 & 3.28 & & & \\
\hline & Empathy & $40+$ & 29.41 & 2.50 & .01 & 996 & \\
\hline & Truct & Under 40 & 14.72 & 2.25 & 07 & 045 & \\
\hline & Trust & $40+$ & 14.76 & 1.64 & -.07 & .945 & \\
\hline & Modesty & Under 40 & 7.67 & 1.43 & 30 & 700 & \\
\hline & Niodesty & $40+$ & 7.82 & 1.24 & -.59 & .100 & \\
\hline & Coonerotion & Under 40 & 19.28 & 2.26 & 106 & 200 & \\
\hline & Cooperation & $40+$ & 18.53 & 2.65 & 1.00 & .290 & \\
\hline Conscientiousnecs & & Under 40 & 104.5 & 11.25 & & & \\
\hline Conscientiousness & & $40+$ & 101.12 & 10.91 & 1.03 & .307 & \\
\hline & Drive \& Solf Discinlin & Under 40 & 51.97 & 9.07 & 113 & & \\
\hline & Drive \& Selt-Discipline & $40+$ & 48.12 & 9.46 & 1.43 & .160 & \\
\hline & Dependability \& & Under 40 & 50.81 & 10.12 & 66 & 51 & \\
\hline & Reliability & $40+$ & 49.00 & 6.99 & .00 & .51 & \\
\hline & Orcanization & Under 40 & 50.64 & 9.60 & 75 & 460 & \\
\hline & Organization & $40+$ & 48.35 & 12.05 & .15 & .400 & \\
\hline & & Under 40 & 49.25 & 8.97 & & & \\
\hline & Deliberation & $40+$ & 49.47 & 10.42 & -.08 & 940 & \\
\hline
\end{tabular}




\section{Macrothink}

International Journal of Human Resource Studies

ISSN 2162-3058

2022, Vol. 12, No. 1

Table 3. Race / Ethnicity Means, Standard Deviations, t-Tests, and Effect Size

\begin{tabular}{|c|c|c|c|c|c|c|c|}
\hline & & Race/Ethnicity & $M$ & $S D$ & $t$ & $p$ & $d$ \\
\hline \multirow{8}{*}{ Stress Response } & & Majority & 33.97 & 4.40 & \multirow{2}{*}{1.16} & \multirow{2}{*}{.252} & \\
\hline & & Minority & 32.29 & 5.38 & & & \\
\hline & \multirow{2}{*}{ Irritability } & Majority & 8.87 & 2.09 & \multirow{2}{*}{1.84} & \multirow{2}{*}{.071} & \\
\hline & & Minority & 7.64 & 2.27 & & & \\
\hline & \multirow{2}{*}{ Impulsivity } & Majority & 15.26 & 2.01 & \multirow{2}{*}{-.26} & \multirow{2}{*}{.797} & \\
\hline & & Minority & 15.43 & 2.47 & & & \\
\hline & \multirow{4}{*}{ Social Discomfort } & Majority & 9.85 & 2.05 & \multirow{2}{*}{.92} & \multirow{2}{*}{.363} & \\
\hline & & Minority & 9.21 & 2.64 & & & \\
\hline \multirow{10}{*}{ Extraversion } & & Majority & 66.56 & 6.67 & \multirow{2}{*}{-1.30} & \multirow{2}{*}{.111} & \\
\hline & & Minority & 69.43 & 8.19 & & & \\
\hline & \multirow{2}{*}{ Warmth } & Majority & 20.90 & 2.01 & \multirow{2}{*}{-1.67} & \multirow{2}{*}{.001} & \\
\hline & & Minority & 22.07 & 2.84 & & & \\
\hline & \multirow{2}{*}{ Assertiveness } & Majority & 15.38 & 2.09 & \multirow{2}{*}{-1.01} & \multirow{2}{*}{.317} & \\
\hline & & Minority & 15.36 & 2.62 & & & \\
\hline & \multirow{2}{*}{ Gregariousness } & Majority & 12.59 & 2.41 & \multirow{2}{*}{-1.50} & 140 & \\
\hline & & Minority & 13.50 & 2.44 & & .140 & \\
\hline & A stivity I eyel & Majority & 17.69 & 2.91 & 24 & 738 & \\
\hline & Activily Lever & Minority & 18.50 & 4.03 & -.24 & .150 & \\
\hline Flexibility & & Majority & 29.15 & 4.09 & -137 & 177 & \\
\hline Flexibility & & Minority & 31.00 & 3.96 & -1.31 & $.1 / 1$ & \\
\hline & Intellectual Curiosity & Majority & 14.64 & 2.96 & -84 & 407 & \\
\hline & mentectual curiosity & Minority & 15.50 & 2.95 & -.84 & & \\
\hline & Onenness to Change & Majority & 14.51 & 2.16 & -152 & 135 & \\
\hline & Upenness to Cnange & Minority & 15.50 & 1.45 & -1.52 & .135 & \\
\hline A areeoblenecs & & Majority & 71.10 & 5.04 & 140 & 167 & \\
\hline Agreedolentess & & Minority & 70.36 & 8.42 & -1.40 & .107 & \\
\hline & Empathy & Majority & 29.49 & 2.27 & -36 & 726 & \\
\hline & Limpaniy & Minority & 29.21 & 4.64 & .00 & .120 & \\
\hline & Trust & Majority & 14.97 & 1.65 & -93 & 355 & \\
\hline & & Minority & 14.07 & 2.89 & -.93 & & \\
\hline & Modecty & Majority & 7.79 & 1.28 & -41 & 683 & \\
\hline & Modesty & Minority & 7.50 & 1.61 & -.41 & .083 & \\
\hline & Cooperation & Majority & 18.85 & 2.23 & -170 & 096 & \\
\hline & cooperation & Minority & 19.57 & 2.82 & -1.10 & .090 & \\
\hline Conscientiousness & & Majority & 101.79 & 11.11 & -180 & 077 & \\
\hline 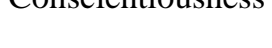 & & Minority & 107.93 & 10.34 & -1.00 & .01 & \\
\hline & Drive \& Self-Discinline & Majority & 48.89 & 8.88 & -192 & 061 & \\
\hline & & Minority & 55.40 & 8.89 & -1.92 & & \\
\hline & Dependability \& & Majority & 48.82 & 7.80 & -157 & 122 & \\
\hline & Reliability & Minority & 53.8 & 11.61 & -151 & .122 & \\
\hline & Oroanization & Majority & 48.66 & 10.57 & 07 & 337 & \\
\hline & & Minority & 53.07 & 9.48 & - & . 531 & \\
\hline & Deliberation & Majority & 47.34 & 8.71 & 258 & 013 & 77 \\
\hline & Demoeration & Minority & 54.33 & 9.35 & -2.00 & . .015 & .11 \\
\hline
\end{tabular}




\section{Discussion, Implications, and Limitations}

This study sought out to measure the degree to which the CH-PA scales and subscales contributed to an adverse impact on a sample of CBC officers. This analysis was conducted by using independent sample t-tests to explore the differences in CH-PA scale and subscale scores in relation to $\mathrm{CBC}$ officer gender, race, and racial/ethnic status. Results from these analyses found that, other than for one $\mathrm{CH}-\mathrm{PA}$ scale and four subscales, $\mathrm{CH}-\mathrm{PA}$ scales and subscales did not significantly differ based on gender, race, or racial/ethnic status.

Readers should note that, although statistically significant differences may exist, these differences may be trivial in real-world situations and may not contribute to discrimination, cause an adverse impact, and infringe on federal guidelines. The magnitude or size of the difference observed (i.e., effect size) is a critical factor to consider when interpreting the statistically significant differences observed in this study (Gravetter \& Forzano, 2011; Sullivan \& Feinn, 2012). Tests of significance inform readers about the probability that the observed difference between two groups was due to chance. Therefore, tests of significance do not provide information as to whether the difference found is valuable or meaningful. Effect size, on the other hand, informs readers about how meaningful the difference is between groups. Effect sizes are commonly seen as being large, or as having practical significance in real-world applications, when they reach and exceed .80. Effect sizes are considered small, or as having a trivial real-world effect, when they are at .2 or lower (Bhandari, 2020; Cohen, 1988).

The direction of a scale score difference (e.g., males scoring higher than females) should also be considered when interpreting whether a difference between groups may impact discrimination in the hiring process or infringe on federal hiring guidelines. The ADEA and Civil Rights Act of 1964 prohibit employment discrimination based on gender, age, and racial/ethnic status. Based on these guidelines, violations and sanctions occur when there is a discriminatory or disparate impact on individuals who are 40 or older, female, or from a minority racial or ethnic status (i.e., protected populations). This should not be interpreted as meaning a disparate impact toward people 39 years of age or younger, male and/or who are Caucasian is accepted or appropriate, but rather these employment selection laws and guidelines only pertain to protected populations.

The following paragraphs consider these aforementioned factors with the differences observed in this study. The gender difference observed in this study consisted of male CBC officers scoring higher on the Irritability subscale of the CH-PA compared to female CBC officers. The Irritability subscale measures an examinee's propensity to feel and express frustration, irritation, and possible anger toward others. Higher scores indicate a greater tendency toward becoming easily frustrated and angry, while lower scores indicate greater frustration tolerance (Tatman, 2019a). Higher scores are more concerning than lower scores when it comes to CBC officers (Tatman, 2019a). Since males scored moderately higher on this scale than females, federal laws and guidelines pertaining to disparate impact do not apply to this observed difference.

The age differences observed in this study consisted of CBC officers who were under 40 
years of age scoring higher on the Flexibility scale and its Openness to Change subscale compared to $\mathrm{CBC}$ officers who were 40 years of age or older. The Flexibility scale score is a combination of its two subscale scores: Openness to Change and Intellectual Curiosity. Therefore, it does not have its own, unique interpretation. The Openness to Change subscale measures an examinee's openness to change and variety in their life. High scores suggest that the examinee is open to changes in their life, while low scores suggest the individual likely prefers routine and consistency in their life (Tatman, 2019a). The difference observed in this stud may suggest that officers under 40 may be more open to changes in their routine and be more open to new ideas, theories, and ways of thinking compared to officers 40 years of age or older. The magnitude or size of this difference, however, was only found to be moderate. In other words, in real-world situations, the degree to which this difference would make a noticeable impact on hiring decisions is likely small. Another aspect suggesting that this difference will likely have little impact on hiring decision is based on the Flexibility scale and its Openness to Change subscale showing no correlation or predictability with future job performance ratings (Tatman, 2019a). Therefore, these scales provide users with descriptive information about the applicant, as opposed to predictive estimates about how those traits will impact future job performance. Therefore, the degree to which these differences would likely contribute to a discriminatory hiring decision is minimal.

The race/ethnicity difference found in this study consisted of Minority CBC officer applicants scoring higher on Deliberation than compared to the Majority $\mathrm{CBC}$ officer applicants. Deliberation measures how much time the examinee spends before making a decision, communicating, or engaging in a behavior. Higher scores indicate a preference toward more deliberation and careful consideration, while lower scores indicate a preference toward thinking and acting quickly (Tatman, 2019a). This would suggest that Minority participants in this study scored in a direction that would suggest they tend to spend more time deliberating about decisions, actions, or comments they make compared to Majority participants. Higher scores on this subscale have been associated with better job performance ratings compared to individuals scoring lower (Tatman, 2022). Therefore, based on how the groups differ (i.e., Minority participants scoring higher than Majority participants), and the direction of the scores (i.e., higher scores are associated with better job performance ratings), this observed difference does not violate or infringe on federal guidelines or would cause an adverse impact.

These findings contribute to existing research on the CH-PA and have implications for CBC hiring agencies using the CH-PA. Researchers have found that $\mathrm{CH}-\mathrm{PA}$ scales and subscale scores significantly correlated with, and predicted, supervisor rating of job performance (Tatman, 2019a). The present findings contribute to this existing research by identifying that the CH-PA does not only correlate with and significantly predict supervisor rating of job performance, but that these scales and subscales do not appear to contribute to an adverse impact on $\mathrm{CBC}$ applicants based on their gender, age, racial/ethnic status. This finding is important for $\mathrm{CBC}$ hiring agencies using the $\mathrm{CH}$-PA because it provides supportive evidence that the CH-PA complies with federal hiring laws and guidelines. Federal guidelines such as the ADEA and Title VII of the Civil Rights Act of 1964 prohibit employment selection 
processes from discriminating against applicants based on gender, age, and racial/ethnic status. Results from this study provide CBC hiring agencies using the CH-PA with empirical evidence that $\mathrm{CH}-\mathrm{PA}$ scale and subscale scores do not contribute to discrimination that would infringe on and violate federal hiring guidelines.

There are a couple limitations with this study that are noteworthy. First, the sample size for this study was relatively small. Although this study's sample size was adequate for the statistical procedures conducted, scale score differences from a small number of participants could have changed the results obtained in this study. Therefore, these results should be read with a degree of caution and awareness about the impact sample size could have had on these results. The second limitation is regarding the geographic region from which this sample was obtained. Participants in this study came from three Midwestern CBCs. Although the racial/ethnic composition in this study is consistent with the geographical region from which it was taken (Census Reporter, 2019; Statistical Atlas, 2018) results may differ with samples taken from other regions of the country.

\section{Conclusion}

This study measured the degree to which the CH-PA may contribute to an adverse impact on a sample of $\mathrm{CBC}$ officer applicants based on gender, age, and racial/ethnic status. Results obtained from this study revealed that CH-PA scale and subscales scores did not differ in a manner that would violate federal hiring guidelines or would cause an adverse impact on CBC applicants based on their gender, age, or racial/ethnic status. These findings have implications for the $\mathrm{CBC}$ hiring process by providing $\mathrm{CBCs}$ with empirical evidence that the $\mathrm{CH}-\mathrm{PA}$ does not contribute to discriminatory hiring decisions and is compliant with federal hiring guidelines. This finding is valuable as $\mathrm{CBCs}$ use the $\mathrm{CH}-\mathrm{PA}$ as part of their hiring process by providing information that suggests results obtained from the CH-PA do not contribute to discrimination and are in line with federal hiring guidelines. Additional research is recommended that explores the degree to which $\mathrm{CH}$-PA scores differ based on scores obtained from protected populations from more urban, densely populated, and culturally diverse $\mathrm{CBCs}$ and institutions to help contribute to the generalizability of these findings.

\section{References}

Bhandari, P. (2020, February 18). What is effect size and why does it matter? https://www.scribbr.com/statistics/effect-size/

$\begin{array}{llll}\text { Census (2019). Reporter } & \text { Midwest }\end{array}$ https://censusreporter.org/profiles/02000US2-midwest-region/

Cohen J. (1988). Statistical Power Analysis for the Behavioral Sciences. Routledge Academic

Costa, P. T., Jr., \& McCrae, R. R. (1992). NEO PI-R professional manual. Odessa, FL: Psychological Assessment Resources.

Digman, J. M. (1990). Personality structure: Emergence of the five-factor model. Annual Review of Psychology, 41, 417-440. doi:10.1146/annurev.ps.41.020190.002221 


\section{Macrothink}

International Journal of Human Resource Studies ISSN 2162-3058 2022, Vol. 12, No. 1

Gravetter, F., \& Forzano, L. (2011). Research methods for the behavioral sciences. Cengage Learning.

Ones, D. S., Dilchert, S., Viswesvaran, C., \& Judge, T. A. (2007). In support of personality assessment in organizational settings. Personnel Psychology, 60(4), 995-1027. https://doi.org/10.1111/j.1744-6570.2007.00099.x

Statistical Atlas (2018). Race and Ethnicity in the Midwest. https://statisticalatlas.com/region/Midwest/Race-and-Ethnicity

Sullivan, G. M., \& Feinn, R. (2012). Using effect size - or why the $p$ value is not enough. Journal of Graduate Medicine Education, 4(3), 279-282. https://doi.or/10.4300/JGME-D-12-00156.1

Tatman (2022). Personality Traits of Top Probation and Parole Officers: Identifying High Performing Probation and Parole Officers with the Critical Hire-Personality Assessment [Manuscript submitted for publication]. Critical Hire.

Tatman, A. W. (2019a). Initial Reliability and Validity of the Critical Hire-Personality Assessment. Corrections: Policy, Practice and Research. https://doi.org/10.1080/23774657.2019.1699477

Tatman, A. W. (2019b). Pre-Employment Integrity Testing: The Missing Piece in the Correctional Officer Hiring Process. Perspectives, 43(3), 36-41.

Tatman, A. W. (2021). 3 Assessments That Will Help Correctional Agencies Hire Top Performers. Perspectives, 45(3), 55-63.

Tatman, A. W., \& Huss, M. T. (2020). Initial reliability and validity for the Critical Hire Screen. Personnel Assessment and Decisions, 1, 1-14.

Uniform Guidelines on Employee Selection Procedure (1978); 43 FR 38295. (1978, August 25). http://uniformguidelines.com/uniformguidelines.html\#20

Wiggins, J. S. (1996). The five-factor model of personality: Theoretical perspectives. The Guilford Press.

\section{Copyright Disclaimer}

Copyright for this article is retained by the author(s), with first publication rights granted to the journal.

This is an open-access article distributed under the terms and conditions of the Creative Commons Attribution license (http://creativecommons.org/licenses/by/4.0/). 